\title{
Management of English Language Anxiety through Behaviour Modification Techniques of High School Students
}

\author{
Ganesan, Rajesh $^{1 *}$, Kulkarni, Mukund ${ }^{2}$
}

\section{ABSTRACT}

Today we live in the age of globalization, as the world came at calling distance the need for the common communication system has aroused which is understood and well accepted by the global community. As nation we also have understood and accepted the importance of common communication system to have firm footing in the global scenario. With some exception English language has acquired the status of global language, which is spoken, written, understood and used by many world countries including India. In India English has become pre-requisite and facilitating factor in communication, education, vocation and business careers. But still in India we speak and use diverse languages, that's why Indian scenario is quite different from that of world. On the basis of English language Indian population can be divided in to two main groups. First group includes people who are very good at all aspects of English language like reading, writing, speaking and understanding it. They are mostly urban, middle or high class people, having easy access to good education and they use it to their advantage. Remaining population is mostly rural, lower income group and depends on public schools for their education. Mostly these people know only their native language and communicate in it only. Being second language and started at later age, English learning creates anxiety in students of this population, associated with productive skills like speaking and writing or receptive skills like reading and listening. English anxiety is a feeling of uneasiness, worry, nervousness, apprehension, or fear while learning or using English. Children in this population study English as second language at High School level in almost all schools; except English all other subjects are taught to them in their native language. The effects of this anxiety are more evident in the classroom and strongly indicate the Academic performance of the student. Anxiety is found to have a detrimental effect on student's confidence, Self-esteem and level of participation. Anxious students employ avoidance strategies like falling sick frequently, not paying attention in classroom and skipping classes. They do well in other subjects but not in English, which lowers their self esteem; as result they develop negative attitude toward English language, and show less interest in this subject. Anxious students also forget previously learned material, volunteer answers less frequently and have a greater tendency to remain passive in classroom activities. When these

\footnotetext{
${ }_{1}^{1}$ Assistant Professor, Department of Psychology, Tripura Central University, Tripura

${ }^{2}$ Research Scholar (Psychology), R \& D Centre, Bharathiar University, Coimbatore

*Responding Author

(C) 2016 I G Rajesh, K Mukund; licensee IJIP. This is an Open Access Research distributed under the terms of the Creative Commons Attribution License (http://creativecommons.org/licenses/by/2.0), which permits unrestricted use, distribution, and reproduction in any Medium, provided the original work is properly cited.
} 


\section{Management of English Language Anxiety through Behaviour Modification Techniques of High School Students}

students finish their high school and joins junior colleges at cities they are taught science subjects in English only. This sudden change does not go well with them and creates definite anxiety, which hampers their learning process. Just because they are not good at English they start lagging behind and feel inability to compete with other students which are good at English. The frustration of not being able to understand the subject matter well further creates anxiety in them; most of the students could not overcome this anxiety and fail to achieve their desired goals.

Unfortunately educational institutes are unaware about this important cause behind students' turmoil and subsequent non performance; which is wrongly attributed to the aptitude of the student. That is why this issue has not been given due attention and consideration at school and college level. Therefore there is acute need to introduce innovative psychological strategies to alleviate anxiety towards English.

Through the application of Behaviour Modification Techniques at high school level English language anxiety can be reduced to the minimum considerable level and students interest in the subject can be increased many fold. This will boost their confidence and self esteem and encourage their participation in the class. The feeling of 'we can also' and newly found interest in the subject will help in improving their language. This will definitely reflect in their academic performance and will further boost and increase their confidence and interest. Improvement in English language will help them in understanding other subjects which are taught in English in better way. Therefore this study is undertaken to reduce English Language anxiety through Behaviour Modification Techniques. This is a pilot study of 30 students who are studying in standard VIII at Nutan Kundakeshwar Vidyamandir. When their last unit test scores referred, it was understood that all these students are academically above average and do well in all subjects except English. When they assessed on the Foreign Language Classroom Anxiety scale by Horwitz, E. K., Horwitz, M. B., \& Cope (1986) (translated in Marathi for present study) they showed high level of English language anxiety. All these students were taught about the interventions to be used and they practiced these interventions for a month. Result shows the significant drop in mean anxiety of group from pre-intervention score 120.57 to post-intervention score 101.07 and significant increase in their Post scholastic mean score 20.87 from 17.97 prescholastic mean score. These results are very significant and encouraging.

\section{Interventions used are:}

i) Reduction of Rate of Breathing (Ganesan, 2012).

ii) Laughter Technique (Ganesan, 2008).

iii) Development of Alternate Emotional Responses to the Threatening Stimulus (Ganesan, 2008).

iv) Fun of Failing Technique (Ganesan, 2014). 


\section{Management of English Language Anxiety through Behaviour Modification Techniques of High School Students}

After one month of intervention, when these students were reassessed for anxiety level and performance on English test they showed significantly less anxiety level and significant improvement in their unit test. Their hesitation while communicating and writing in English has almost vanished and they showed renewed interest and confidence. These results are very encouraging and show that Behaviour Modification Techniques are efficient in treating English Language Anxiety.

Keywords: English Language Anxiety, Behaviour Modification Techniques, Native language.

\section{INTRODUCTION}

Behaviour Modification Techniques use simple principle that when overt maladaptive behaviours are modified and replaced by more adaptive and useful behaviors, the neural mechanism which controls these responses also gets modified and the new modified bahaviors become our way of responding to those same stimulus situations. Behaviour Modification Techniques have their basis in classical learning theories of Pavlov and Skinner, which are used to treat some of psychological ailments. Learning principles states that through proper application of reinforcement and punishment; maladaptive behaviours can be changed and replaced with adaptive ones. Maladaptive behaviours are conditioned responses and they can be changed by using Behaviour Modification Techniques. Basic principle of learning theories is that, when we consistently respond to a stimulus in a particular manner, neural network is formed and it becomes our way of responding to those particular stimuli. Feeling of anxiety is our maladaptive response to the stressful or threatening stimuli. When students starts learning English, they have positive approach toward it but when it becomes evident that it is not easy and repeated attempts of them are not paying off, they become frustrated and anxious. So now for them learning English has become stressful stimulus and anxiety as their natural response. Certain amount of anxiety is good and has positive effect on individuals as it can push them to master it, but too much of it has debilitating effect and makes individual helpless and exhaust their coping skills. Anxiety is the learned response to the English learning and so can be unlearned and replaced by the adaptive response. On the basis of Reciprocal Inhibition, adaptive or alternate responses are formed and anxiety is replaced with them.

Most of the students have problem in productive skills like writing and speaking; because when they try to do it, they could not easily remember the English words and become conscious about it which further increases their anxiety. The feeling, "others will laugh when they will come to know about my inability" and the conscious effort to speak or write it in totally correct way adds to the problem and leads to the total avoidance. So to avoid the feeling of anxiety and subsequent uneasiness they acquire avoidance strategy, and it naturally worsens their progress in learning English language. Same thing happens with the other subjects those are taught in English at college level and here it hits them like thunderbolt because only successful completion of this 


\section{Management of English Language Anxiety through Behaviour Modification Techniques of High School Students}

stage opens the gates of the opportunities. So from the point of view of these students it is a grave problem and needs immediate remedy.

Simple but effective Behaviour Modification Techniques of the Ganesan were successfully used to treat different types of anxieties in the past but never used before to manage English Language anxiety. Hence there is a need for systematic evaluation of the efficacy of Behaviour Techniques in the Management of English Language Anxiety. The prime aim of this study is to ascertain the effectiveness of Behaviour Modification Techniques in reducing English language anxiety among high school students and the possibility of implementing these techniques to larger possible population.

\section{METHODOLOGY}

It is a pilot study of 30 Marathi speaking students who are studying in standard VIII ${ }^{\text {th }}$ at Nutan Kundakeshwar Vidyamandir, who have shown high anxiety level when were assessed on the Foreign Language Classroom Anxiety scale by Horwitz, E. K., Horwitz, M. B., \& Cope, J (1986) modified for the Indian context (Marathi version) . Before giving interventions to these students their performance on English language unit test was also recorded as measure of student's achievement in the English language.

\section{Interventions:}

The following interventions were given for one month:- i) Reduction of Rate of Breathing (Ganesan, 2012), ii) Laughter Technique (Ganesan, 2008) iii) Development of Alternate Emotional Responses to Threatening Stimulus (Ganesan, 2008), and iv) Fun of Failing Technique (Ganesan, 2014).

First three techniques were used to make them comfortable and relaxed around threatening stimulus (English language), due to which their generalized anxiety and passive approach toward English considerably subsidized. Fourth intervention helped them to overcome their hesitation.

\section{RESULTS}

After one month of intervention all students were reassessed for English language anxiety level and performance on English unit test. Almost all students have shown significant drop in their anxiety level when Foreign Language Classroom Anxiety scale by Horwitz, E. K., Horwitz, M. B., \& Cope, J (1986) (Marathi version) was administered to them again, and after intervention when they faced another unit test of English language they showed marked improvement in their performance, which was reflected in their test scores. Subjective assessment by English teacher also pointed out to the increased concentration and interest of the students in subject and to the confidence while speaking in the classroom. 
Table 1: English Anxiety and Scholsatic Score of the Group Before and After Intervention $(N=30)$

\begin{tabular}{|l|c|c|c|c|}
\hline Factors & $\begin{array}{c}\text { Before } \\
\text { Intervention } \\
\text { Mean } \\
\text { (SD) }\end{array}$ & $\begin{array}{c}\text { After } \\
\text { Intervention } \\
\text { Mean } \\
\text { (SD) }\end{array}$ & $\begin{array}{c}\text { Mean } \\
\text { Difference }\end{array}$ & $\begin{array}{c}\text { Critical } \\
\text { Ratio }\end{array}$ \\
\hline English & 120.57 & $\begin{array}{c}101.07 \\
(6.80)\end{array}$ & 19.50 & $17.20^{* *}$ \\
Language & $(7.16)$ & & & \\
Anxiety & 17.97 & $\begin{array}{c}20.87 \\
(2.05)\end{array}$ & 2.90 & $9.18^{* *}$ \\
\hline Scholastic & $(2.76)$ & & & \\
Score & & & & \\
\hline
\end{tabular}

** $\mathrm{P}<0.01$

\section{DISCUSSION}

The purpose of the present pilot study was to assess the efficacy of Behaviour Techniques in reduction of English language Anxiety. For the objective assessment of English language Anxiety, a psychometric scale, namely, Foreign Language Classroom Anxiety scale by Horwitz, E. K., Horwitz, M. B., \& Cope, J (1986) modified for Indian context (Marathi Version) was used. As measure of student's achievement in English language their unit test scores out of 30 were recorded before and after intervention. The pre-intervention mean anxiety score was 120.57 with SD 7.16 and mean scholastic score was 17.97 with SD 2.76. To overcome the English language Anxiety, interventions based on the Behaviour Modification Techniques were taught to the students and for one month practiced by them. It is known that the sympathetic nervous system gets activated when we face threatening, anxiety provoking and stressful situation and prepares our body for fight or flight; it increases rate of breathing to fulfill the increased demand of the oxygen. In our case, increased rate of breathing is the natural response to the threatening stimulus learning English. The reduction of rate of breathing technique deliberately establishes a non-compatible response to the threatening stimulus i.e. when faced with the anxious situation of learning English a more relaxed and adaptive but non-compatible response of reducing rate of breathing is elicited through training and practice. This response is naturally elicited by parasympathetic nervous system to calm down the body after the activation by the sympathetic nervous system. Many studies have shown that laughter is very effective coping or stress reducing mechanism, which activates brains reward center Nucleus accumbence. Reiss a professor of psychiatry says that reward center is evolved to enhance learning and behaviour through positive feedback, it's meant to allow people to learn from and perform in their environment in as optimal a way as possible. Laughter also activates brain to release a feel good neurotransmitter endorphin, which helps to reduce stress produced by the English learning. Development of alternate response like anger, laughter, love and worship are incompatible to the English learning helps to replace anxiety through reciprocal inhibition. Fourth technique deliberately used to lessen their hesitation to speak or write in English, as it helped them to 


\section{Management of English Language Anxiety through Behaviour Modification Techniques of High School Students}

overcome their uneasiness and fear of failure. As result they started speaking and writing in English without any inhibitions and fear was replaced by fun. Through this technique they were made to understand that it is always better to fail than giving up trying. These techniques helped these English anxious students to unlearn maladaptive response, that is feeling of anxiety and learn slightly funny but more adaptive response through reciprocal inhibition toward English Language. Learning studies have proved that, when brain repeatedly does certain things in a particular way, it becomes habit through formation of neural networks. In this case also student's brains were trained through practice to respond to the English language by more adaptive response and not to respond by anxious response. This in turn boosted their confidence and self esteem and they started showing added interest in the subject. All students responded well to the interventions.

Group's post-intervention anxiety mean score was reduced to 101.07 with std. deviation 6.80, critical ratio 17.2056 and mean difference 19.50. It shows the significant drop in the anxiety level of the group. Group's post-intervention scholastic mean score was increased to 20.87 with SD 2.05, critical ratio 9.1865 and mean difference 2.90. It shows that their performance on English language unit test improved significantly. It means that Behaviour Modification Techniques used as interventions have not only reduced anxiety of these students but also helped them to achieve more in their English language unit test. Increased achievement measure is the result of increased interest in the subject and regained confidence. It also helped them to overcome their hesitations and inhibitions while communicating in English. To conclude, this study has shown that Behaviour Modification Techniques are efficient in treating English Language Anxiety and if these interventions are practiced for extended period they will definitely further improve the English learning experience of the students.

\section{REFERENCES}

Ganesan, V. (2008, a) Development of Alternate Emotional Responses to the Threatening Stimulus. Unpublished Paper. Global Institute of Behaviour Techniques, Coimbatore.

Ganesan, V. (2008, b) Development of Laughter Technique for the Management PsychoPhysiological Stress Responses. Unpublished Paper. Global Institute of Behaviour Techniques, Coimbatore.

Ganesan, V. (2011) Management of Darkness Phobia. Unpublished paper. Global Institute of Behaviour Techniques, Coimbatore.

Ganesan, V. (2012) Development of a Brief Behaviour Techniques for the Reduction of Rate of Breathing. Unpublished Paper. Global Institute of Behaviour Techniques, Coimbatore.

Horwitz, E. K., Horwitz, M. B., \& Cope, J. (1986). Foreign language classroom anxiety. The Modern Language Journal, 70(2), 125-132.

Wolpe, J. (1969) The Practice of Behavioral Therapy, New York: Pergamon. 
How to cite this article: G Rajesh, K Mukund (2016) Management of English Language Anxiety through Behaviour Modification Techniques of High School Students, International Journal of Indian Psychology, Volume 3, Issue 3, No. 5, DIP: 18.01.085/20160303 